\title{
Local phase shift from Acropora-dominant to Condylactis-dominant community in the Tiao-Shi Reef, Kenting National Park, southern Taiwan
}

Received: 12 December 2003 / Accepted: 19 January 2004 / Published online: 2 September 2004

(C) Springer-Verlag 2004

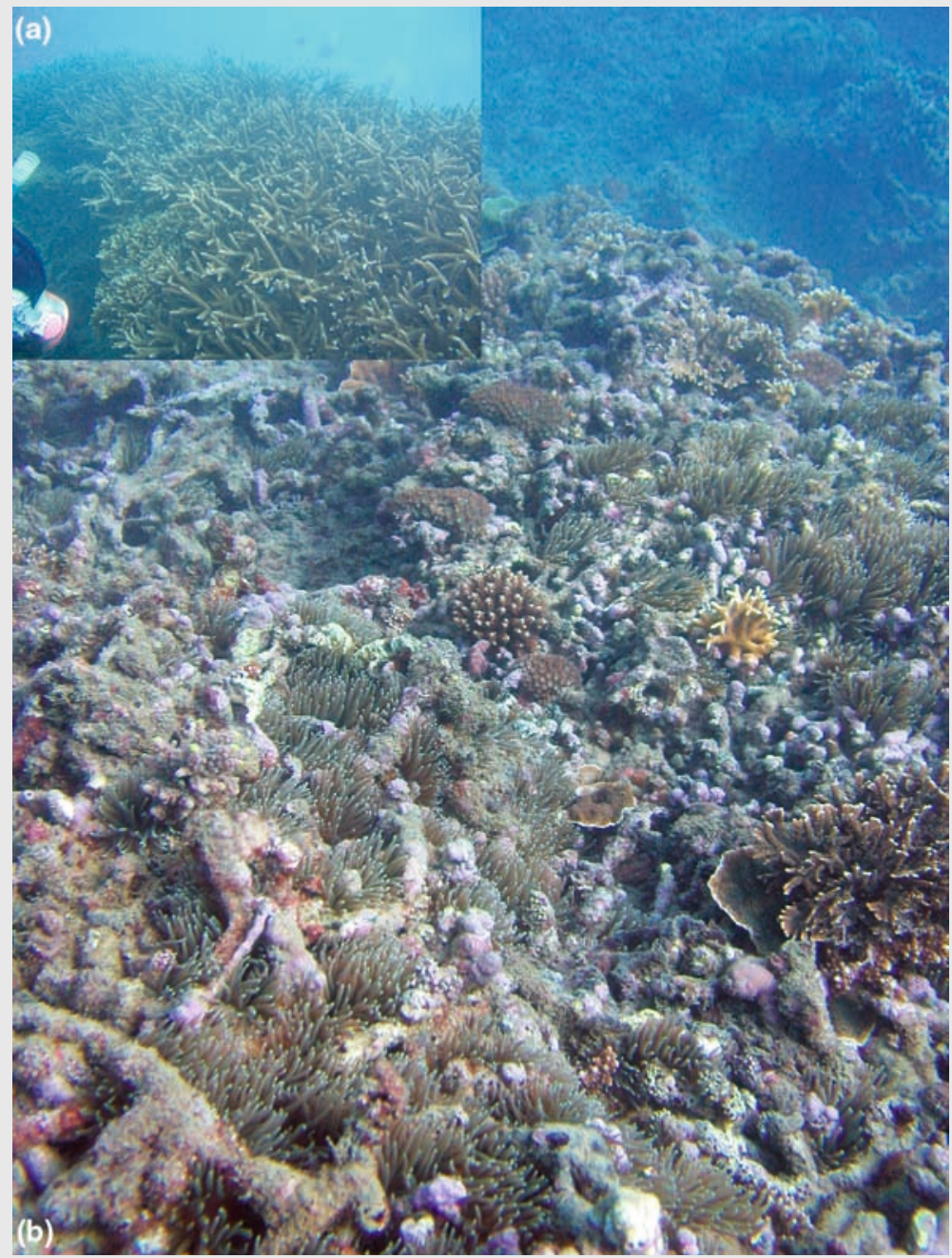

Fig. 1a, b a $A$. muricata patch; b Acropora debris covered by dense sea anemone, Condylactis sp.

C. A. Chen $(\bowtie)$

Research Center for Biodiversity and Institute of Zoology, Academia Sinica, 115, Taipei, Taiwan E-mail: cac@gate.sinica.edu.tw

Tel.: + 886-2-27899549

Fax: + 886-2-27858059

C.-F. Dai

Institute of Oceanography, National Taiwan University, 106 Taipei, Taiwan
In 1992 at Tiao-Shi Reef $\left(21^{\circ} 55^{\prime} \mathrm{N}, 120^{\circ} 46^{\prime} \mathrm{E}\right)$, Kenting National Park, southern Taiwan, the coral community was characterized by scleractinian corals with Acropora spp. patches dominant between depths of 5 to $15 \mathrm{~m}$ (A. muricata, Fig. 1a; Dai 1993). This reef has suffered from pressures of overfishing, coastline development, and tourism in the last two decades (reviewed in Dai 1997). ReefCheck-conducted surveys between 2000 and 2003 indicated that some Acropora patches were replaced by the sea anemone, Condylactis sp.

(Fig. 1b). Statistical comparison of surveys conducted in 1987 and 1997 demonstrated a significant decrease in the average number of species $(21$ to 16), average number of colonies (35 to 29), coral coverage (47 to 41 ), and species diversity (2.63 to 2.23 ) in the Tiao-Shi Reef over a decade (Dai et al. 1998, 1999). Areas occupied by Condylactis sp. may reduce the recruitment of coral larvae, and subsequently delay the recovery of coral community. Causes of Condylactis sp. outbreak are still unknown, but have been correlated to the consequences of Typhoon Herb in 1996, the 1997 mass coral bleaching, landslides, sewage run-off, and tourist impact in the Kenting National Park (Dai. et al. 1998, 1999). Proper management and a long-term ecological research plan are endorsed to ensure the recovery of the coral community in the Tiao-Shi Reef and the sustainability of the Kenting National Park.

\section{References}

Dai CF (1993) Pattern of coral distribution and benthic space partitioning on the fringing reefs of southern Taiwan. Mar Ecol 42:185-204

Dai CF (1997) Assessment of the present health of coral reefs in Taiwan. In: Grigg RW, Birkeland C (eds) Status of Coral Reefs in the Pacific. Sea Grant Program, University of Hawaii, pp 123-131

Dai CF, Kao KM, Chen YT, Chaun ST (1998) Changes of coral communities in the Nan-wan Bay, Kenting National Park from 1987 to 1997. Bull Natl Park 8:79-99 (in Chinese)

Dai CF, Kao KM, Chen YT, Chaun ST (1999) Changes of coral communities in the eastern and western coast, Kenting National Park from 1987 to 1997. Bull Natl Park 9:111-129 (in Chinese)

\section{Reê Sơ⿱⺈巴丶S}

Coral Reefs (2004) 23: 508 DOI 10.1007/s00338-004-0423-9 